\title{
CPAP INCREASES BRONCHIAL REACTIVITY IN OSAS PATIENTS
}

\section{P. Korczyński, K. Górska, P. Bielicki, K. Byśkiniewicz, J. Zieliński and R. Chazan}

Travel grant for Sleep Medicine, sponsored by Wein-mann Geräte fur Medizin GmbH \& Co. KG

Dept of Pneumonology, Medical University, Warsaw, Poland

WINNING ABSTRACT: Continuous positive airways pressure (CPAP) is a well known and safe method of treatment patients with obstructive sleep apnoea syndrome (OSAS). The effects of CPAP administration on the upper respiratory tract are known. However its effects on the lower respiratory tract still needs to be determined. Studies on bronchial hyperreactivity in patients treated by CPAP are contradictory.

The aim of the study was to assess the influence of a 3-week CPAP treatment in patients with OSAS and to evaluate associations between changes in bronchial reactivity and clinical features of OSAS and lung function tests (LFT).

Patients with newly diagnosed OSAS and lack of infection or chronic illness of the respiratory tract or other conditions which could influence bronchial hyperreactivity (BHR) were included.

Investigations were performed in 101 patients. There were 88 males and 13 females, mean age $51.5 \pm 11.2$ years and BMI $32.6 \pm 5.4 \mathrm{~kg} \cdot \mathrm{m}^{-2}$. Qualified patients were randomly divided into 2 groups: 76 patients to CPAP treatment group, 25 control group. Both groups did not differ in anthropometrics features, severity of OSAS and LFT. Metacholine challenge test (MchCT) was performed at baseline and repeated after 3 weeks. Analysis of the individual results showed that in 11 patients the MchCT was positive ( 6 in the CPAP and 5 in the control groups). After 3 weeks in the group of CPAP treated patients an increase of BHR was noted. Log PC20M decreased from $1.38 \pm 0.3$ to $1.26 \pm 0.5(p<0.05)$. The number of patients with a positive result in the MchCT increased from 6 to 16 patients. There was no significant change in BHR in the control group.

It was found that CPAP treated patients with BHR were older, had less severe OSAS and lower FEV1 ( $<<0.05)$. In none of the patients positive result of BHR did no affect compliance to CPAP treatment.

Conclusions: CPAP therapy increases bronchial reactivity, but does not affect compliance to treatment.

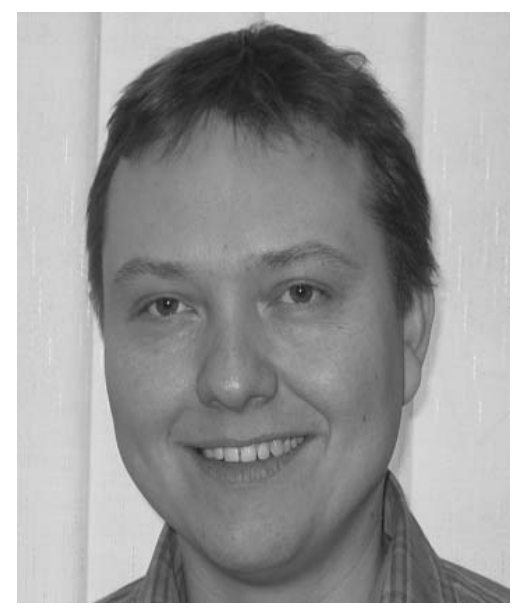

Piotr Korczyński

Dept of Pneumonology, Warsaw Medical University, Warsaw, Poland

\section{SYNOPSIS OF MY JOB AND THE ROLE OF THE UNIT IN WHICH I WORK}

I work in the Dept of Pneumonology at Warsaw Medical University, Warsaw, Poland. I currently work as a doctor and lecturer. Our department is the clinical department of the

STATEMENT OF INTEREST: None declared. medical school and, along with my colleagues, I am involved in the practical aspect of teaching the third, fifth and sixth year medical students internal medicine. Besides my teaching work I am also involved in research within the sleep laboratory. This part of the department was built at the beginning of the 1990s. I am part of a team lead by the head of the department, Prof. Ryszarda Chazan, who has also been my supervisor and a tremendous role model for me as a scientist and physician. I must also thank Prof. Jan Zielinski and all my colleagues for their contributions to my work, their ideas and comments.

\section{SYNOPSIS OF MY RESEARCH AND HOW MY WINNING POSTER IS PART OF THIS}

In January 2007, I received my PhD degree with my work entitled "The influence of continuous positive airways pressure for bronchial reactivity in patients with obstructive sleep apnea syndrome." Continuous positive airway pressure (CPAP) is an acknowledged and safe method of treating obstructive sleep apnoea syndrome (OSAS) with minimal complications. The effects of CPAP administration on the upper respiratory tract are known; however, its influence on the lower respiratory tract still needs to be determined. Studies on bronchial hyperreactivity in patients treated by CPAP showed that CPAP treatment can either increase or decrease the bronchial reactivity. Variations noted during the period of treatment, positive pressure values in the respiratory tract generated by the CPAP device, or smoking had no influence on the development of the hyperreactivity. 


\section{HOW MY RESEARCH WILL IMPACT ON CLINICAL OR} RESEARCH PRACTICE

OSAS is a severe medical problem. According to Polish epidemiological data obtained by PłYWACZEWSKI et al. [1], we suspect OSAS occurs in $16.7 \%$ of males and $5.4 \%$ of females. In total, 676 subjects were examined out of 1,186 randomly chosen inhabitants of Warsaw aged 41-72 yrs. The diagnostic criteria were similar to the most frequently cited epidemiological research by Young et al. [2].

As we know now, the most effective method of treating a patient with sleep apnoea is positive pressure, so this method is widely used in Poland. However, according to our study we should measure pulmonary function in all patients at follow-up.

\section{REFERENCES}

1 Pływaczewski R, Bednarek M, Jonczak L, Zielinski J. Sleepdisordered breathing in middle-aged older Polish urban population. J Sleep Res 2008; 17: 73-81.

2 Young T, Palta M, Dempsey J, Skatrud J, Weber S, Badr S. The occurrence of sleep-disordered breathing among middle-aged adults. N Engl J Med 1993; 328: 1230-1235. 